\title{
Matemática e Música: a história da relação e evolução de duas Ciências através dos tempos ${ }^{1}$
}

\author{
Lucas Teixeira da Silva*, Claudia Lisete Oliveira Groenwald**
}

\section{Resumo}

Apresenta-se neste artigo um histórico que evidencia a relação da matemática com a música e o seu desenvolvimento através dos tempos, com o objetivo de apresentar possíveis alternativas didáticas para se contextualizar os conceitos e conteúdos matemáticos em sala de aula. Esse material é resultado de uma pesquisa de iniciação científica, de um estudante do curso de Licenciatura em Matemática, juntamente com o Grupo de Estudos Curriculares de Educação Matemática (Gecem) do Programa de pós-Graduação em Ensino de Ciências e Matemática (PPGecim), da Universidade Luterana do Brasil, campus Canoas/RS. Desde as frações de pequenos números inteiros do tamanho de uma corda, dos pitagóricos, até os logaritmos musicais de Sebastian Bach, a música e a matemática possuem profundas relações, as quais evoluíram em sincronia conforme os avanços da ciência e do entendimento acerca dos fenômenos do som. Expõe-se essas relações em uma cronologia temporal, além de apresentar reflexões sobre o ato de contextualizar os conteúdos e seus reflexos na aprendizagem dos conceitos matemáticos.

Palavras-chave: Educação Matemática; Matemática e Música; História da Música; Sons.

\section{Introdução}

A música se faz presente desde o início da história da humanidade. Nas primeiras aglomerações sociais, nas tribos, os tambores rústicos feitos com madeira e pele de animais conseguiam expressar sentimentos de medo, ansiedade, afeição e outras sensações que fugiam a razão, em um período histórico onde a forma de comunicação era rudimentar e limitada. Isto começou a dar forma ao jeito que os seres humanos se

* Licenciado pelo curso de Matemática da Ulbra no campus Canoas/RS - Brasil. E-mail: luccas.txs@gmail.com

** Doutora em Ciências da Educação pela Universidade Pontifícia de Salamanca, Espanha. Professora do Curso de Matemática Licenciatura e do Programa de Pós-graduação em Ensino de Ciências e Matemática da Ulbra/ Canoas. E-mail: claudiag@ulbra.br

Recebido em: 17/09/2018 - Aceito em: 30/09/2018.

https://doi.org/10.5335/rbecm.v1i2.8977 
expressavam, evoluindo para as danças, gravuras, esculturas e demais meios que posteriormente compunham o que hoje se conhece como arte.

Das grandes civilizações do mundo antigo até a sociedade contemporânea, a música passou por um processo de evolução, fortemente influenciado por fatores regionais e socioeconômicos. Nesse sentido, a pergunta que se busca responder neste artigo é: qual é a relação entre matemática e música e de que forma a matemática teve impacto na evolução do aspecto musical?

Percebe-se que a linha de evolução das ferramentas matemáticas coincide com a evolução da música enquanto ciência. Por exemplo, o som não era visto como um fenômeno físico até que as relações entre funções trigonométricas e eventos ondulatórios fosse clara. Evoluindo no contexto musical, as relações entre diferentes instrumentos e harmonia entre notas musicais não era devidamente padronizada até a relação desses conceitos com o universo dos logaritmos. E, ainda sobre a evolução dessa relação, o estudo de harmônicos que compõem um som deve-se à evolução do cálculo e do estudo sobre equações diferenciais, a forma complexa de análise e estudo do espectro sonoro.

Tais exemplos tornam possível perceber a forte relação e conexão entre os assuntos matemática e música. Atualmente, esses temas não são devidamente explorados e contextualizados nos conteúdos matemáticos nas escolas.

O autor Oscar João Abdounur, em seu livro Matemática e Música (2015), busca enfatizar as implicações educacionais da contextualização dos conteúdos matemáticos através da música e de como a experimentação em sala de aula, com o uso das teorias aprendidas, deixa marcas nos alunos e os fazem refletir sobre a usabilidade do conhecimento que lhes está sendo apresentado em seu cotidiano.

Dentre outros argumentos que buscam defender e justificar a relação da matemática juntamente com conceitos musicais nas escolas da Educação Básica, este artigo tem o enfoque em asseverar e explicitar as relações existentes entre matemática e música e de que forma esses assuntos podem ser inseridos no âmbito escolar.

\section{Referencial Teórico}

Para corroborar a importância de se trabalhar esses assuntos em conjunto em sala de aula, o principal aspecto a ser analisado é o da devida contextualização dos conteúdos matemáticos, dando sentido usual ao que se aprende, e ao pensamento analógico, fazendo relação de conceitos conhecidos com novos conceitos através de analogias.

Em uma breve reflexão, o alto nível de abstração exigido pela matemática aliado a falta de contextualização ade- 
quada dos conteúdos, produz dificuldades no ensino e aprendizagem dos conceitos matemáticos. Como exemplo, pode-se citar o desenvolvimento do conteúdo de funções, que, muitas vezes, é desenvolvido sem contextualização com a sua usabilidade em situações do cotidiano, também como análises financeiras ou modelagem de pequenos fenômenos físicos.

$\mathrm{O}$ ato de contextualizar está definido nos Parâmetros Curriculares Nacionais do Ensino Médio - PCNEM (BRASIL, 2000):

O critério central é o da contextualização e da interdisciplinaridade, ou seja, é o potencial de um tema permitir conexões entre diversos conceitos matemáticos $\mathrm{e}$ entre diferentes formas de pensamento matemático, ou, ainda, a relevância cultural do tema, tanto no que diz respeito às suas aplicações dentro ou fora da Matemática, como à sua importância histórica no desenvolvimento da própria ciência (p. 43).

Ainda defendendo a importância da contextualização no âmbito da melhor assimilação dos estudantes do conteúdo trabalhado, de acordo com Tufano (2001), contextualizar é o ato de colocar no contexto, ou seja, colocar alguém a par de alguma coisa; uma ação premeditada para situar um indivíduo em lugar no tempo e no espaço desejado.

Nesse sentido, a contextualização através de analogias propõe formas de desenvolver os conteúdos que visam facilitar a compreensão e a assimilação desses. Isso é evidenciado, principalmen- te em sala de aula, em diferentes perfis de aprendizagem por parte dos alunos, estes possuindo diferentes formas de assimilação e compreensão dos conteúdos. Para Armstrong (2001), na teoria das múltiplas inteligências de Gardner, a inteligência pode ser expressa em uma gama de múltiplas competências, sendo elas a lógico-matemática, linguística, corporal-cinestésica, espacial, intrapessoal e a musical (p. 14-15). Como exemplo, tem-se alunos com características de aprendizado mais voltadas ao aspecto visual, utilizando de representações para o teste de hipóteses, ou ainda, o aluno mais processual, aquele focado na forma da resolução de um problema através de algoritmos e processos mecânicos. Para Abdounur (2015), evidenciar conhecimentos através de analogias, focando nas semelhanças do que já é conhecido, favorece a assimilação de novas ideias e esquemas (p. 204). Com isso, fica evidente que o papel do professor no século XXI é o de proporcionar esses diferentes momentos de aprendizagem sobre um mesmo tema para atingir um maior número de alunos.

[...] a música é um tipo de arte com imenso potencial educativo já que, a par de manifestações estéticas por excelência, explicitamente ela se vincula a conhecimentos científicos ligados à física e à matemática além de exigir habilidade motora e destreza que a colocam, sem dúvida, como um dos recursos mais eficazes na direção de uma educação voltada para o objetivo de se atingir o desenvolvimento integral do ser humano (SAVIANI, 2003. p. 40). 
Ainda sobre contextualizar os conteúdos, esse ato permite que haja interdisciplinaridade entre áreas e assuntos, dinamizando a relação entre conteúdos até então distintos, deixando o processo de ensino e aprendizagem com mais sentido e mais completo.

No assunto escolhido para este artigo, pode-se trabalhar as funções trigonométricas, relacionando a sua representação gráfica à representação geométrica do som e suas características, que por sua vez, podem evoluir para o ensino da música enquanto arte. Outra oportunidade a ser evidenciada configura-se no fato de a música ser um processo cultural que se deu desde a pré-história até os tempos modernos, o mesmo torna-se um assunto carregado de história e de uma visão sobre diferentes sociedades ou momentos históricos. Desde a música nas igrejas na Idade Média, até a música renascentista do século XIV, essas estão carregadas de história, de interesses sociais e acompanham a evolução das ciências, envolvendo seus aspectos filosóficos, tornando-se assim um assunto com grande riqueza para a sala de aula.

A música auxilia na aprendizagem de várias matérias. Ela é componente histórico de qualquer época, portanto oferece condição de estudos na identificação de questões, comportamentos, fatos e contextos de determinada fase da história. Os estudantes podem apreciar várias questões sociais e políticas, escutando canções, música clássica ou comédias musicais. O professor pode utilizar a música em vários segmentos do conhecimento, sempre de forma prazerosa, bem como na expressão e comunicação, linguagem lógico-matemática, conhecimento científico, saúde e outras. Os currículos de ensino devem incentivar a interdisciplinaridade e suas várias possibilidades (CORREIA, 2003, p. 84-85).

Além das possibilidades de práticas interdisciplinares nesses assuntos, o estudo do fenômeno sonoro e, posteriormente, do universo musical, facilita a introdução de tecnologias digitais em sala de aula, uma vez que, para a análise do espectro sonoro, existem uma gama de softwares e aplicativos que, de uma forma visual, ajudam ao professor a reforçar a teoria e mostrar sua implicação prática. Segundo Santos (2012) o momento atual pode promover reflexões acerca da utilização dos aparatos digitais, como smartphones, tablets, computadores, calculadoras, de modo que possam enriquecer intervenções pedagógicas nos processos de ensino e aprendizagem. Como exemplo, tem-se o software GeoGebra, que possui reconhecimento mundial como uma ferramenta para o estudo de álgebra, cálculo e geometria dinâmica. Com ele é possível traçar diferentes gráficos no mesmo plano, analisando suas características, semelhanças e variando parâmetros. Além disso, ele dispõe de um recurso pouco conhecido que diz respeito à emissão de sons através do gráfico de funções periódicas. Segundo o NCTM (2015), para uma aprendizagem signi- 
ficativa da disciplina de matemática, a tecnologia deve ser considerada como uma característica indispensável em sala de aula (p. 78).

Para finalizar, o ensino de música nas escolas é assegurado pela Lei de Diretrizes e Bases da Educação Nacional ( $\mathrm{n}^{\circ}$ 12.796, de 2003) em seu parágrafo $2^{\circ}$ que discorre "O ensino da arte, especialmente em suas expressões regionais, constituirá componente curricular obrigatório nos diversos níveis da educação básica, de forma a promover o desenvolvimento cultural dos alunos" complementado pelo parágrafo $6^{0}$ que formaliza: "As artes visuais, a dança, a música e o teatro são as linguagens que constituirão o componente curricular de que trata o $\S 2^{\circ}$ deste artigo."

A seguir, serão apresentadas algumas das relações existentes entre matemática e música seguindo uma linha cronológica na evolução do pensamento e das ferramentas tecnológicas de ambos os assuntos.

\section{Monocórdio de Pitágoras}

Por mais que haja registros do surgimento da música como forma de expressão de sentimentos no período pré-histórico, foi por volta do século VI a.C. que se começou a pensar no estudo da música. $\mathrm{O}$ precursor desses estudos foi Pitágoras de Samos, famoso teórico matemático. Segundo a lenda, Pitágoras após ouvir os sons de martelos que soavam harmonicamente em uma ferraria, resolveu investigar as relações harmônicas existentes entre os sons. Para isso, construiu um instrumento denominado "monocórdio", que se tratava de uma caixa de ressonância sobre a qual era estendida uma única corda presa a dois cavaletes em suas extremidades e um terceiro móvel entre esses dois (Figura 1).

Figura 1 - O Monocórdio de Pitágoras

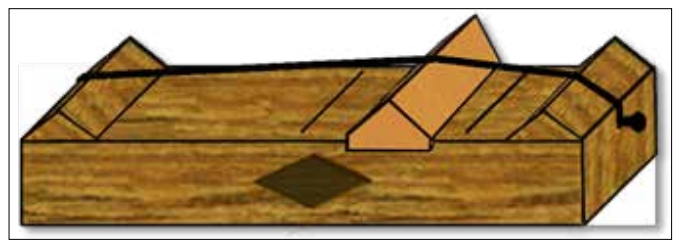

Fonte: <http://clubes.obmep.org.br/blog/wp-content/uploads/ 2016/10/monocordio1.png >

Seu objetivo era o de verificar as relações harmônicas das vibrações da corda conforme as divisões por pequenos números inteiros (até o número 4) em seu tamanho. Aqui cabe deixar claro que, a harmonia sonora corresponde ao conceito de consonância, ou seja, indica a combinação de vários sons simultâneos que são interpretados de forma agradável para o ouvido humano. Outro ponto a evidenciar, é que, para os pitagóricos, existia um misticismo em relação à matemática, à natureza e ao universo, uma vez que os recentes avanços matemáticos da época serviam para descrever perfeitamente diversos fenômenos naturais. O número 4 é um exemplo disso, uma 
vez que é associado às 4 estações, aos 4 elementos, etc.

Em síntese, os pitagóricos acreditavam que tudo no universo era racional e podia ser expresso por números harmoniosamente relacionados. Com o monocórdio, Pitágoras se dispõem a encontrar as relações harmônicas e constituir uma das primeiras escalas musicais da história. Esse experimento é tão impactante que é considerado o primeiro experimento científico da história da humanidade, pois utilizou-se de métodos e regras que mais tarde culminariam no método científico de pesquisa.

Com divisões no tamanho da corda nas frações de $2 / 3$ e $\frac{3}{4}$, Pitágoras estabelece a escala pitagórica através do que ficou conhecido como "ciclo de quintas", uma relação de harmonia sonora de 5 em 5 notas dividindo o tamanho original da corda em $2 / 3$ sucessivamente. Essa escala representou um grande avanço no entendimento sobre as relações sonoras harmoniosas, porém, havia dois problemas principais: o fato de a escala não ser cíclica e o de a distância entre as frequências das notas não ser padronizada. Esses dois problemas não foram resolvidos pelos pitagóricos, pois em determinadas subdivisões, as frações obtidas resultavam em números irracionais, o que era estranho à crença pitagórica. Por essa inconsistência cíclica, diferentes instrumentos acabavam por não soar harmonicamente tocando juntos, por mais que estivessem na mesma nota musical. Isso deve-se ao fato de que diferentes instrumentos possuem diferentes características sonoras. Outro fator notório é que o momento histórico musical evoluía da música monofônica (execução de notas simples) para a polifônica (execução de sons simultâneos e harmônicos entre si).

No decorrer dos séculos seguintes, foram apresentadas diversas tentativas de solução a tais questões, porém, nenhuma foi tão impactante e eficaz quanto a apresentada por Johann Sebastian Bach.

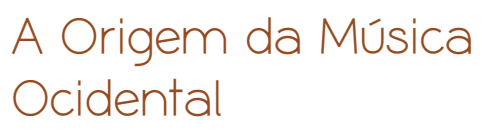

No século XIV, tem-se o período renascentista na história da humanidade, um período marcado pela valorização da ciência e pela busca pelo entendimento e harmonia com a natureza. Essa premissa impacta diretamente nas produções culturais e como a arte é vista pela sociedade. É a partir desse período que a música começa a ser estudada com um caráter técnico, inspirando matemáticos do mundo todo a propor soluções aos problemas de produção musical da época, ocasionado pela escala pitagórica. Com isso, surge Johann Sebastian Bach (1685-1750) que propõe uma nova organização musical baseada em padrões matemáticos. Através de sua obra, "O Cravo Bem 
Temperado", escrito originalmente em 1722 , é proposta a escala temperada, que consiste na organização de 12 notas musicais (resolvendo o problema da distância entre as notas, adicionando semitons, sustenidos e bemóis) e a relação entre as frequências partindo da função $f(x)=2^{\frac{x}{12}}$, o que torna a relação entre as notas musicais uma relação logarítmica.

Figura 2 - Escala Cíclica Logarítmica

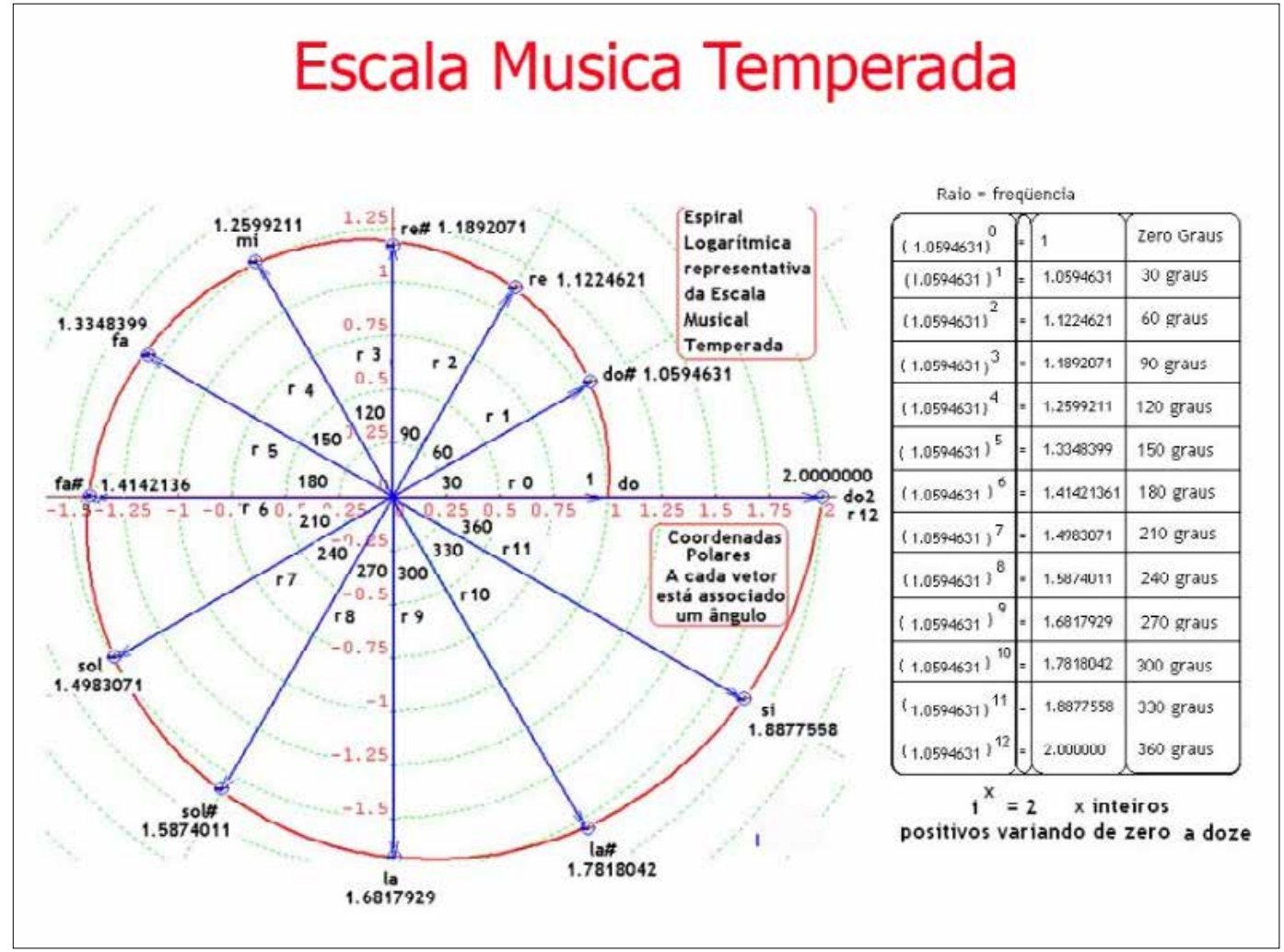

Fonte: <http://blog.santoangelo.com.br/wp-content/uploads/2015/05/IDOOTESMIE-001.jpg>.

Com essa nova organização, os sons naturais, advindos da escala pitagórica, passam a ser sons não naturais, minimamente corrigidos para que essa nova escala seja cíclica e contínua. A diferença e a impressão de desafinação entre os sons de instrumentos distintos, agora é erradicada, proporcionando composições mais ousadas. Esse avanço deu fim ao período renascentista e início ao período barroco, com enfoque em uma música mais dramática e elaborada (as grandes orquestras são um exemplo).

Matematicamente falando, basicamente a ideia de Bach foi a de dividir a diferença entre ciclos, conhecida como 
"coma pitagórica", entre as 12 notas musicais. O resultado é que, o nosso cérebro ignora pequenas diferenças e aceita os sons como harmônicos. Esse fato vem da ideia de limite, uma vez que essa interpretação cerebral na diferença das frequências das notas musicais é semelhante a ideia que $0,999999 \ldots$ é 1 . Um exemplo que evidencia a relação das notas musicais em uma função logarítmica é o formato de um piano, que lembra o gráfico da função $\log (x)$, uma vez que o tamanho das cordas internas ao piano segue essa relação (Figura 3).

Figura 3 - Piano e a Função Logarítmica

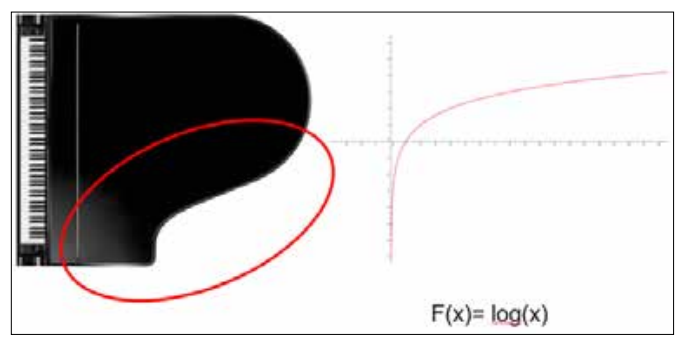

Fonte: autores (adaptada).

Essa modificação deu origem ao padrão ocidental musical.

\section{Outros Padrões Musicais}

Além da escala temperada, existem também outros padrões musicais menos usuais. No oriente, utiliza-se a escala pentatônica, uma variação das cinco primeiras notas da escala pitagórica. A premissa dessa escala é presar por sons naturais e em harmonia com o univer- so (o que vem ao encontro da filosofia oriental). No oriente médio, os Árabes possuem escalas que variam de 22 à 28 notas dependendo da região e também instrumentos específicos. Essas escalas são baseadas em padrões geométricos ou de análise combinatória.

A diferença entre as escalas musicais em distintas regiões do planeta Terra, evidenciam o porquê que músicas árabes possuem sonoridade bem diferentes das orientais, que por sua vez são distintas da música ocidental.

\section{Relação Entre a Matemática e o Som}

A música é o resultado de sucessão de sons harmoniosos e o som é um fenômeno físico estudado e modelado através de ferramentas matemáticas. Inicialmente, salienta-se a relação entre os gráficos das funções seno ou cosseno com o som. O som pode ser definido de duas formas diferentes: "como uma onda mecânica longitudinal que se propaga em meios materiais ou como a sensação auditiva causada pela vibração de um meio material" (CABRAL; LAGO, 2004), podendo esse ser através do ferro, do oxigênio, vidro, entre outros. Esse fenômeno transporta energia sem transportar matéria. Considerando o ar como o material de propagação, o som também pode ser definido como a percepção da vibração, captada pelos ouvidos, de oscilações 
muito rápidas de compressão e rarefação desse. Essas oscilações são representadas geometricamente através de ondas, cujos picos demonstram a rarefação e compressão máximas da onda sonora, essas, modeladas matematicamente pelas funções seno ou cosseno, cujos gráficos são ondulatórios (Figura 4):

Figura 4 - Representação geométrica do som

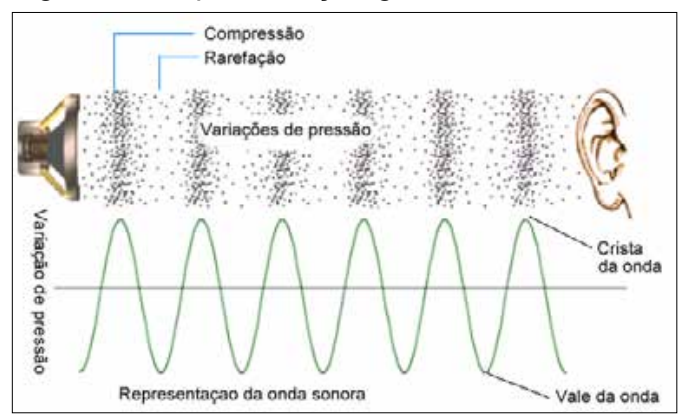

Fonte: <http://www.fq.pt/som/33-propagacao-do-som>.

A velocidade em que as compressões e rarefações ocorrem definem o som que é ouvido, pois isso está diretamente ligado à frequência da onda. Essa frequência é medida no número de oscilações que a perturbação faz em cada unidade de tempo. A unidade de medida da frequência é o hertz $(\mathrm{Hz})$, que representa a quantidade de oscilações por segundo. Quanto maior a frequência, mais agudo é o som, quanto menor a frequência, mais grave é o som obtido.

Com isso, sempre que é necessário realizar o estudo de algum efeito derivado do fenômeno sonoro, utiliza-se a modelagem matemática através de funções trigonométricas, para a manipulação de parâmetros e variações de amplitude, comprimento e frequência das ondas sonoras.

Nesse ponto, se pode fazer a relação ao pensamento analógico, uma vez que sua premissa principal é a de utilizar os conhecimentos já estabelecidos na construção de novos conceitos. Como exemplo, é possível relacionar a frequência de uma onda sonora com um som agudo ou grave e a amplitude dessa onda com o que popularmente é conhecido como "volume" de um som entre outras experimentações. $\mathrm{O}$ objetivo principal é dar significado prático ao que se está aprendendo, mostrando a sua usabilidade no cotidiano.

\section{A Música Digital e o Estudo de Harmônicos}

Na construção das escalas pitagórica e temperada, é possível trabalhar conteúdos e conceitos matemáticos como frações, logaritmos, números racionais e irracionais, potenciação, séries e progressões entre outros assuntos. Essa é apenas uma parte do grande potencial na relação entre matemática e música. A música digital é possível por que hoje se consegue transformar sons em números, ou seja, transformar um fenômeno físico em fórmulas matemáticas.

A relação entre as notas musicais é fundamental na produção e na gravação 
de novas músicas, uma vez que padrões sonoros estimulam a criatividade artística, porém a maior relação entre esses dois temas, música e matemática, se dá no estudo dos timbres.

Cada onda sonora possui um formato característico, proveniente do objeto que a emitiu. Esses objetos, por sua vez, podem variar de tamanho, material e até espessura, sendo tais fatores os determinantes do timbre. Por exemplo, um piano e um violino podem tocar a mesma nota musical, e executar exatamente a mesma frequência, porém o formato da onda sonora será diferente, o que faz com que nosso cérebro consiga distinguir os diferentes sons. Na Figura 5 apresenta-se exemplos de diferentes timbres com a mesma frequência.

Figura 5 - Diferentes timbres com a mesma frequência

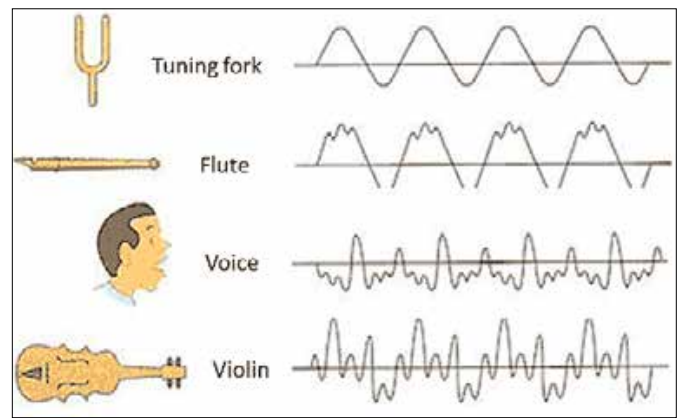

Fonte: <https://aprendapiano.com/wp-content/uploads/2017/06/ Timbres.gif>.

Essa diferença no formato da onda sonora se dá devido aos harmônicos daquele som. Esses harmônicos seriam como o "som através do prisma", uma vez que são as ondas fundamentais que compõem aquele som. Para entender melhor, deve-se pensam um som como uma soma infinita de senos e cossenos, em que cada função somada é um harmônico do som resultante. Quanto mais harmônicos possui um som, mais brilhante é o som obtido, como se observa na Figura 6.

Figura 6 - Harmônicos de um Som

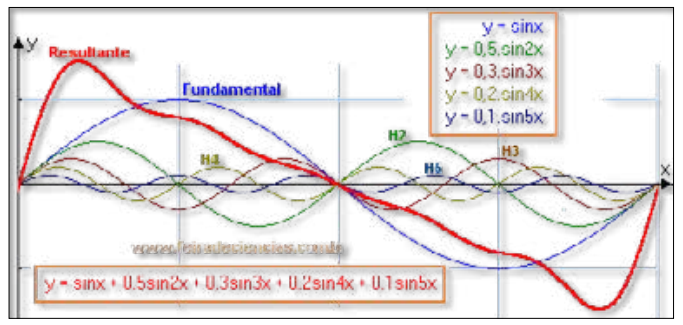

Fonte: <http://www.feiradeciencias.com.br/sala14/image14/14_T05_05.gif>

Neste âmbito, pode ser devidamente contextualizada a aplicabilidade do estudo de séries de Fourier e equações diferenciais, pois são as ferramentas matemáticas utilizadas para "decompor" os sons e compreender a sua natureza.

\section{Considerações Finais}

Conforme exposto, buscando uma melhor assimilação dos conceitos matemáticos por parte dos alunos, a contextualização desses em sala de aula é considerada importante para o desenvolvimento do processo de ensino e aprendizagem da matemática. Observa-se que o uso de analogias é importante, no intuito da criação de significado, porém, esse 
processo requer, do professor, pesquisa e entendimento sobre o assunto exposto.

Considera-se que a apresentação de conteúdos com exemplos de situações do cotidiano proporciona aos estudantes a visualização e a utilização dos conhecimentos do Ensino Médio em situações da vida em sociedade. No caso da música, aliar esse assunto aos conceitos de uma matéria mais técnica pode despertar a curiosidade e o interesse dos estudantes, principalmente do público mais jovem.

Entende-se que o ensino em uma visão interdisciplinar é um dos caminhos que buscam apresentar aos alunos uma ciência com significado, que transcende os muros da segmentação através das matérias, de modo que, muitas vezes, acaba por "afastar" conhecimentos que evoluíram e foram construídos de maneira conjunta. Por exemplo, no assunto escolhido para este artigo, consegue-se relacionar diversos conteúdos matemáticos, nos mais variados níveis de ensino, juntamente a fatores históricos, estudo da física do som e de cultura em forma de arte.

No caso da matemática, é comum alunos e professores acabarem não visualizando o significado do estudo de teoremas e fórmulas, o que distancia os conteúdos de sua aplicabilidade, uma grande perda de oportunidade no âmbito de encantar os estudantes, uma vez que a matemática é a ferramenta que explica os mistérios da natureza e do universo.

\section{Mathematics and Music: the history of the relationship and evolution of two Sciences through times}

\section{Abstract}

This article presents a history that shows how mathematics is related to music and its development over time, with the aim of presenting possible didactic alternatives to contextualize concepts and mathematical contents in the classroom. This material is the result of a Scientific Initiation research, a student of the Mathematics Degree course, together with the Mathematics Education Curriculum Group (GECEM) of the Programa de Pós-Graduação em Ensino de Ciências e Matemática (PPGECIM), of the Univesidade Luterana do Brasil, Canoas/ RS campus. From the small fractions of the whole numbers of a string, from the Pythagoreans, to the musical logarithms of Sebastian Bach, music and mathematics have deep relations, these evolved in synchrony as the advances of the sciences and the understanding about the phenomena of sound. These relations are exposed in a temporal chronology, besides presenting reflections on the act of contextualizing the contents and their reflexes in the learning of the mathematical concepts.

Keywords: Mathematical Education; Mathematics and Music; Music history; Sound.

\section{Nota}

1 Esta pesquisa foi apoiada pela Fapergs com bolsa de iniciação científica durante o curso de Licenciatura pela Universidade Luterana do Brasil (ULBRA). 


\section{Referências}

ABDOUNUR, Oscar João. Matemática e Música. São Paulo: Livraria da Física, 2015.

ARMSTRONG, Thomas. Inteligências múltiplas na sala de aula. Prefácio Howard Gardner. 2. ed. Porto Alegre: Artes Médicas, 2001.

BRASIL. MEC, PCN - Ensino Médio - Parâmetros Legais. MEC, 2000.

CABRAL, Fernando; LAGO, Alexandre. Física. Edição 2004. São Paulo: Harbra, 2004.

CORREIA, Marcos Antonio. Música na Educação: uma possibilidade pedagógica. Revista Luminária, União da Vitória, PR, n. 6, p. 83-87, 2003. (Publicação da Faculdade Estadual de Filosofia, Ciências e Letras de União da Vitória).

NCTM. De los Principios a la Acción - para garantizar el êxito matemático para todos. NCTM: México, 2015.

SANTOS, E. Cibercultura, Educação On-line e Processos Culturais. Teias, v. 3, n. 30, p. 3-8, 2012.

SAVIANI, Dermeval. Revista de Ciências da Educação. Centro Universitário Salesiano de São Paulo, a. 5, n. 9, $2^{\circ}$ sem. 2003.

TUFANO, Wagner. Contextualização. In: FAZENDA, Ivani C. Dicionário em Construção: Interdisciplinaridade. São Paulo: Cortez, 2001. 